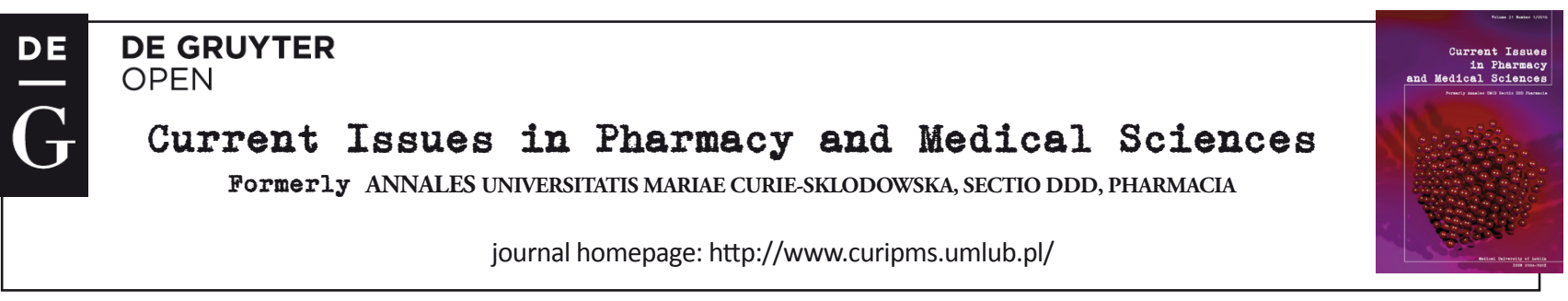

\title{
Rationale for naphazoline effects in-depth study
}

\author{
Borys KuZMinOv $^{1 \star}$, Vira Turkina ${ }^{2}$, Yuriy KuZMinov ${ }^{3}$ \\ ${ }^{1}$ Department of hygiene and prophylactic toxicology, Danylo Halytsky Lviv National Medical University, Pekarska 69, 79010 Lviv, Ukraine \\ 2 Central Research Laboratory and Laboratory of Industrial Toxicology, Danylo Halytsky Lviv National Medical University, Ukraine \\ ${ }^{3}$ Department of Pediatrics, Danylo Halytsky Lviv National Medical University, Ukraine
}

\section{ARTICLE INFO \\ Received 06 October 2016 Accepted 09 November 2017}

\section{Keywords:}

naphazoline,

toxicity,

side effects,

prospects for studies.

\begin{abstract}
This article presents a retrospective review of data on side effects of drugs containing naphazoline and data on toxicity of the agent when entered the body via different pathways. Most publications on clinical signs of possible naphazoline-associated side effects are lacking thorough analysis of possible causes. Limited data on the pharmacokinetics and pharmacodynamics of the drug led to various complications after its administration. Therefore, further studies on naphazoline content dynamics or products of its biotransformation in biological substrates and determination of half-life of the agent must be conducted. This will allow establishingsafe levels for different exposure pathways and harmful levels of the naphazoline with respect to its material accumulation. It should be noted that scientific publications contain controversial data regarding allergenic potential of the agent. Possible side effects of the drug on the reproductionand development are not revealed. Determination of effects the products containing naphazoline may have on immune and reproductive system is an important part of the research.
\end{abstract}

\section{INTRODUCTION}

Naphazoline has been used in clinical practice for more than seven decades. During this time, numerous data was published in the scientific literature regarding its side effects albeit with no thorough analysis of their causes. In order to determine the prospects of this medicinal product via an in-depth study with further identification of the negative effects mechanism, we have collected and analyzed actual material on the side effects of medicinal products containing naphazoline, as well as toxicity studies data with different routes of naphazoline administration, and existing hypotheses and views on the possible naphazoline effect.

\section{METHODS}

A literature review was carried out by way of the PubMed, MEDLINE, Europe PMC databases, and through specialized magazines of Ukraine, Belarus and Russia using the terms "naphazoline", "adrenomimetic" and "imidazoline derivatives".

\footnotetext{
* Corresponding author

e-mail: expertiza39@gmail.com
}

\section{BACKGROUND}

Naphazoline belongs to the sympathetic adrenomimetics, $\alpha 2$-adrenoreceptors stimulators, imidazole derivatives product group [13]. The drug administration leads to vasoconstrictor and anticongestive effects [36].

In clinical practice, this leads to the use of drugs containing naphazoline in otolaryngology - to treat rhinitis and in ophthalmology - to relieve redness, swelling, itching of the eyes caused by a cold, or by allergies and irritation (e.g., the effects of smog, swimming or contact lens wear). Naphazoline was described for the first time in the form of hydrochloride (Privine hydrochloride) and was marketed under the Naphthyzin brand-name in April 1941 [12]. In October 1942, the drug entered the United States market [34]. In 1945, the first information was published on the naphazoline hydrochloride pharmacological effect [49]. Subsequently, the pharmacological publications provided data on the average lethal doses of the drug in different routes of administration, namely intragastric - $1260 \mathrm{mg} / \mathrm{kg}$ (rats), $265 \mathrm{mg} / \mathrm{kg}$ (mice) [37]; subcutaneous - $385 \mathrm{mg} / \mathrm{kg}$ (rats), $170 \mathrm{mg} / \mathrm{kg}$ (mice) [10]; intraperitoneal $-87.8 \mathrm{mg} / \mathrm{kg}$ (mice) [41]; intravenous - $13200 \mu \mathrm{g} / \mathrm{kg}$ (mice) [37]. According to Warren and Werner [43], naphazoline has a relatively high toxicity level after intravenous injection in rabbits; however, it is less toxic after subcutaneous injection in rats and mice. The clinical presentation of naphazoline intoxication in 
dogs included vomiting, bradycardia, cardiac arrhythmia, poor capillary filling time, hypotension, or hypertension, shortness of breath, increased upper respiratory sounds, depression, fatigue, anxiety and hyperactivity. These signs appeared within the period of 30 minutes to 4 hours after exposure [14].

When naphazoline was first introduced into clinical practice, local adverse reactions were reported, with rhinitis medicamentosa as one of their manifestations. In the review study by Ramey [36] on rhinitis medicamentosa, a reference is traced back to 1944 in which Feinberg described a clinical case wherein the patient was afflicted with nasal congestion after using naphazoline hydrochloride, Due to this and other similar cases, in 1946, Lake introduced the term of rhinitis medicamentosa. The characteristic symptoms of rhinitis medicamentosa include nasal congestion without rhinorrhea, postnasal drip or sneezing. A rhinitis medicamentosa experimental modelling demonstrated that the use of naphazoline nitrate ( $3 \mathrm{ml}$ of $0.1 \%$ solution) three times a day for 6 days induced in experimental rabbits, endothelium edema, with narrowing lumen, arterial thrombosis, microcirculation disturbances, altered venules configuration, submucosal glands and connective tissue issues [1]. Further studies by Pukhlyk and Hapaniuk [33] showed that the use of nasal decongestants, in addition to affecting the schneiderian membrane, engendered blood pressure normalization, increased vitality, physical activity in persons with sympathetic imbalance (with dominated parasympathetic type of autonomic nervous activity). This, in turn, results in rapid adherence to adrenaline-like substances, including naphasoline. Thus, while patients, based on the accessibility and non-prescription availability of topical vasoconstrictor agents, are using them increasingly; the term for improved nasal breathing sees rapid reduction and symptoms of local irritation, drying and general toxicity action increase.

Local naphazoline-associated reactions are also manifested by a negative effect on the mucosa ciliary apparatus, namely, inhibition of nasal ciliary beat frequency with subsequent stasis [36]. Experimental studies of naphazoline effect on the ciliary apparatus in white rats allowed tracing the changes in the epithelium with time. In such work, multinucleosis and focal destruction of epithelium cilia were observed two weeks after naphazoline $0.1 \%$ solution intranasal administration. Moreover, surface epithelium destructive changes were observed 3 and 6 months after the beginning of the experiment. These were characterized by complete atrophy of the epithelial lining in specific sites and cilia destruction on the apical surface of the ciliated cells with simultaneous metaplasia. In addition, morphological changes were found in the mucosa layer (lymphohistiocyte infiltration with the presence of eosinophils, intercellular edema and appearance of diluted vessels). The authors suggest that the cause of these changes is the effect of naphazoline by delayed hypersensitivity type with allergenic component [50].

In ophthalmology, naphazoline side effects include blurred vision, irritation, mydriasis, increased or decreased intraocular pressure [23]. In addition, an experiment in rabbit eye showed a reduced aqueous humor flow rate in the eye chamber [30]. Further experimental studies have shown that naphazoline topical application in rabbit eye leads to an increase of endogenous atrial natriuretic peptide and decrease of noradrenaline in the cornea, and significantly increased cyclic nucleotides (cAMP, cGMP) through interaction with imidazoline receptors [29].

Naphazoline systemic vasoconstriction phenomenon causes hypertension and reflex bradycardia, as well as possible vital organ ischemia. It is suggested that central $\alpha$-adrenergic receptors stimulation leads to central nervous system (CNS) depression, ranging from drowsiness to coma, hypotension and respiratory rate decrease - leading to Cheyne-Stokes respiration and pulmonary edema. Other side effects include hypothermia, mydriasis, hyperhidrosis and transient excitation hyperreflexia [45].

A cardiotoxic drug effect is observed in otolaryngology, which is explained by the fact that naphazoline bioavailability is more than $50 \%$ [45]. Other authors point to a significant naphazoline resorptive effect, but note the lack of information on its bioavailability and blood serum concentration [28]. Naphazoline systemic effects in otolaryngology may be due to direct adsorption into the nasal mucosa, and partial absorption of the drug when swallowed into the stomach [17]. Naphazoline hypotensive activity was established experimentally in the early stages of its study in dogs [7], cats [49] and rats [20]. In experimental conditions of naphazoline concentrations ranging from $0.5 \mathrm{mM}$ to $10 \mathrm{mM}$ in a normal MacEwen solution, cardiac contractures were induced in rats and guinea pigs. Similar results were obtained in studies of frog heart [3]. The CNS effect of naphazoline is clearly demonstrated by a clinical case of a patient who suffered from chronic headaches associated with excessive use of the drug [9]. In addition, ischemic and hemorrhagic strokes were reported associated with naphazoline when administered nasally [6,51].

Naphazoline associated systemic effects are also observed in ophthalmological practice, and are manifested by headache, hypertension, cardiac disorders, anxiety, nausea, dizziness, weakness and sweating [23].

A similar pattern of naphazoline systemic toxicity is manifested in the case of inadvertent swallow. As long ago as in 1948 a case was described of naphazoline hydrochloride intoxication upon ingestion, which was manifested clinically increased pulse rate, hypertension and partial respiratory rhythm disturbance [47]. Modern literature provides several cases of drug ingestion clinically accompanied by similar symptoms and even acute pulmonary edema [11], or liver and kidney dysfunction [31].

Nasal decongestants in children primarily bring about systemic toxicity. This is a symptomatic sign of the adrenomimetic effect (neurological status disorders, changes in the cardiovascular system, hypothermia, and constriction of pupils) that can appear as a result of "therapeutic" doses $[2,15,42]$. Currently, this situation has no clear explanation, but one possible reason for this may be that the relative area of the nasal mucosa in children is significantly larger as opposed to that of adults, hence a larger area of drug resorption is available. In addition, the average therapeutic dose of certain vasoconstrictor agents (e.g. Naphthyzin) approaches their toxic dose, therefore, there is a high probability of overdose and systemic toxic effects on other organs with 
an expressed adrenergic innervation of blood vessels (brain, heart, digestive tract, etc.). A further cause of decongestant intoxication in children may be the immature mechanism of neuronal adrenoceptor agonist reuptake in presynaptic terminals and insufficient activity of inactivating enzymes $[21,35]$. Additional evidence of patient age sensitivity to naphazoline effect is in geriatric patient response to conjunctival drug application. In high concentrations, it can probably release the granule pigment of the iris in the elderly [23].

In order to understand the naphazoline resorptive capacity, study results are of a great importance. Watanabe et al. [44], in an experiment on loach skin samples (Misgurnus anguillicaudatus Cantor) in vitro, found that drug transfer through the skin is associated with the passive diffusion mechanism. Herein, the naphazoline permeability constant (Kp, cm.h-1) was $9.2 \times 10^{(-2)}$. Signs of local toxic effects of drugs containing naphazoline include rash, flushing and itching [16]. In contact with the skin, the drug at a concentration of $1 \%$ brings about allergic reactions, as confirmed by the prick test $[8,48]$. What is more, the potential was demonstrated of naphazoline capacity to act as a photosensitiser [40].

It should be noted that according to the United States Food and Drug Administration (FDA) classification of drugs allowed for use during pregnancy, naphazoline is " $\mathrm{C}$ "-classified. That is, no clinical trials were conducted and experiments in animals showed adverse effects on the fetus. Recent publications indicate that naphazoline can cause narrowing of the arterial duct or its closure in fetus, when the mother used the drug during pregnancy [18].

In addition, it was experimentally shown that the photolysis products of naphazoline react with DNA, thereby contributing to its damage under aerobic and anaerobic conditions [40]. This causes concern in terms of drug safety.

Hypotheses regarding pathogenesis of these local negative effects of naphasoline are based on generally accepted physiological and biochemical mechanisms of adrenoreceptors action. The likely mechanism of adrenoceptor agonists systemic effect is that vasoconstriction occurs in postsynaptic $\alpha 2$-adrenergic receptors stimulation in vascular smooth muscle cells (VSMC) [3]. Rhinitis medicamentosa can thus result from secondary reduction in endogenous sympathetic noradrenaline production through a feedback mechanism. In addition, it is assumed that drug-induced vasomotor rhinitis is caused by receptor - smooth muscle imbalance of nasal blood flow and cavernous plexus of lower and middle nasal turbinates. In turn, this process is related to the fact that $\alpha 2$-adrenoceptor agonists cause contraction of blood vessels and cavernous bodies in 3-12 hours, which eventually depletes the receptor-smooth muscle apparatus. As a result it becomes relaxed after termination of the adrenoceptor agonist effect and nasal mucosa achieves maximum blood content. This leads to the closure of nasal passages and pronounced nasal congestion in reflex areas [17]. Another hypothesis links rhinitis medicamentosa with ischemia of the nasal mucosa caused by intensive stimulation of arteriocular adrenergic receptors.

Naphazoline adrenal-like activity explains the specified facts of its system activity. The peripheral $\alpha$-adrenoreceptors have a significant impact on the cardiovascular system regulation. They have been found in kidneys and can regulate renal blood flow [38], however, current data on the functioning and localization of adrenoreceptors [24] suggest that they are involved in the regulation of almost all organs and body systems. Thus, the naphazoline effect is a physiological response heterogeneity to the adrenoceptor agonists effect. Currently, there is no full understanding of how the receptors act physiologically and data on their localization and distribution is limited.

The side effects of naphazoline use in ophthalmology can be probably explained by the fact that naphazoline acts indirectly through the central regions of receptors in the brain and directly through the peripheral areas of effector targets [30]. It is assumed that the reason for change in the intraocular pressure when using naphazoline is the possible neuroendocrine function of the ciliated epithelium [4,32]. Natriuretic peptide excreted from the ciliary epithelial cells can then act in a autocrine and/or paracrine way. However, the understanding of how these eye neuroendocrine systems are modulated is limited.

It is suggested that the naphazoline neurotoxicity effect is attributable to the fact that $\alpha$-adrenergic receptors are linked to G-proteins, generating a cascade of events, which in turn leads to arachidonic acid and nitric oxide synthesis. The release of these compounds leads to inflammatory vasodilation [46], which can cause migraine attacks. Hypothetically, naphazoline nitrate can promote synthesis and excretion of additional nitrogen oxide through the naphazoline salt chemical recovery. Furthermore, prostaglandins and nitric oxide contribute to the activation of pain receptors and pain impulse transfer from the periphery to the centre [39].

The discovery of the imidazoline receptors made it more complicated to understand possible naphazoline systemic exposure. Currently, the idea is being developed that imidazoline receptors and adrenoceptors act jointly in the implementation of functional responses to adrenoceptor agonists such as the imidazoline derivatives. They are substantially similar and have close functional relationship. Calcium channel stimulation with adrenoreceptor agonists is a possible way in which such involvement comes about in the functioning of imidazoline receptors agonists. Imidazoline receptors are shown to be located in the brain, heart, kidneys and the pancreatic beta cells. Accordingly, they can modulate various functions of the body [19].

\section{CONCLUSIONS}

The presented literature review is relevant due to the widespread use of naphazoline. Limited pharmacokinetics and pharmacodynamics data of the drug result in mass complications in the form of rhinitis medicamentosa, cardiovascular system disorders, and toxic complications. Thus, further studies are necessary regarding naphazoline content dynamics or its biotransformation products in biological substrates. Such work should include establishing the halflife periods that will allow determining the hazardous level in terms of material accumulation and prognosticating safe exposure levels. To understand the mechanism of action of any drug, as well as it possible toxic effects, the accumulation of knowledge is of a great importance whether 
the compound effect is caused by the original substance moleculular action or its biotransformation products, or both factors simultaneously. It should be noted that the literature data is controversial regarding the allergic potential of the compound. The possible reproductive and developmental negative effects are not covered. Indeed, the study of its immune and reproductive exposure hold relevant areas of research.

\section{REFERENCES}

1. Agha-Mir-Salim P, Stange T, Knipping S, Jahnke V, Berghaus A. Electron microscopic studies of the rabbit nasal mucosa after short-term application of naphzoline nitrate. Laryngorhinootologie. 2001;80(7):389-93.

2. . Bucaretchi F, Dragosavac S, Vieira RJ. Acute exposure to imidazoline derivatives in children. J Pediatr (Rio J). 2003;79(6):519-24.

3. Chapman RA, Leoty C. Which of caffeine's chemical relatives are able to evoke contractures in mammalian heart? Recent Adv Stud Cardiac Struct Metab. 1975;7:425-30.

4. Coca-Prados M, Escribano J, Ortego J. Differential gene expression in the human ciliary epithelium. Prog Retin Eye Res. 1999;18(3):403-29.

5. Corey JP, Houser SM, Ng B A. Nasal congestion: a review of its etiology, evaluation, and treatment. Ear Nose Throat J. 2000;79(9):690-702.

6. Costantino G, Ceriani E, Sandrone G, Montano N. Ischemic stroke in a man with naphazoline abuse story. Am J Emerg Med. 2007; 25(8):983.

7. Craver BN, Chase F, Yonkman FF. Pharmacologic studies of a new vasoconstrictor: 2-Naphthyl-1'-Methyl- imidazoline hydrochloride (Privine or Naphthazoline: J Pharmacol Exper Therap. 1944;82(3):275-87.

8. De Groot AC. Patch testing. 3rd edition: Update 2008 - 2015. Wapserveen, The Netherlands: acdegroot publishing; 2015:33.

9. Di Lorenzo C, Coppola G, La Salvia V, Pierelli F. Nasal decongestant and chronic headache: a case of naphazoline overuse headache? F1000Res. 2013;2:237.

10. Drugs in Japan. Ethical Drugs. $6^{\text {th }}$ edition. Japan: Yakugyo Jiho Co., Tokyo; 1982:612.

11. Fukushima $\mathrm{H}$ et al.: Acute pulmonary edema associated with naphazoline ingestion. Clin Toxicol (Phila). 2008;46(3):254-6.

12. Hild AM. Privine Ciba, a new preparation for reducing congestion of the nasal mucosa. Schweiz med Wchnschr. 1941;71:557-61.

13. Johnson DA, Hricik JG. The pharmacology of alpha-adrenergic decongestants. Pharmacotherapy. 1993;13(6 Pt 2):110-115.

14. Kahn CM, The Merck Veterinary Manual. 9th edition. Whitehouse Station, NJ, [Great Britain]: Merck \& Co.; 2005:2526.

15. Kampi Yu, Dyachuk V. Peculiarities of clinical features of poisoning by topical (nasal) decongestants of children. Scientific bulletin of Uzhhorod university, series Medicine. 2013;48:58-62.

16. Lee DH, Yun S Y, Cho KH, Lee HM, Choi YH. A case of naphazoline intoxication after the ingestion of a topical antiseptic solution. Hong Kong J Emerg Med. 2010;17:364.

17. Lopatin A S. Nasal decongestants: old drugs and new formulations. Doktor.Ru. 2011;65(6):13-9.

18. Lopes LM, Carrilho MC, Francisco RP, Lopes MA, Krebs VL, Zugaib M. Fetal ductus arteriosus constriction and closure: analysis of the causes and perinatal outcome related to 45 consecutive cases. The Journal of Maternal-Fetal \& Neonatal Medicine. 2016;29(4):638-45.

19. Lowry JA, Brown JT. Significance of the imidazoline receptors in toxicology. Clinical Toxicology. 2014;52(5):454-69.

20. Maling HM, Gho AK, Horakova Z, Williams M. A. The pharmacologic effects of ST-155 (Catapres) and related imidazolines in the rat. Pharmacology. 1969;2(6):337-51.

21. Marushko Y. Experience of application of topical decongestants in children of early age. Lechaschiy Vrach. 2010;11:86.

22. Mashige KP. Ocular allergy. Health SA Gesondheid. 2017;22:112-22.

23. McEvoy GK. AHFS Drug information 2006, Naphazoline hydrochloride, Bethesda: American Society of Health-System Pharmacists. 2006:2827-8.
24. McGrath JC. Localization of $\alpha$-adrenoceptors: JR Vane Medal Lecture. British journal of pharmacology. 2015;172(5):1179-94.

25. Mortuaire $\mathrm{G}$ et al. Rebound congestion and rhinitis medicamentosa: nasal decongestants in clinical practice. Critical review of the literature by a medical panel. European annals of otorhinolaryngology, head and neck diseases. 2013;130(3):137-44.

26. Munaron L. Shuffling the cards in signal transduction: Calcium, arachidonic acid and mechanosensitivity. World J Biol Chem. 2011;2(4):59-66.

27. Musshoff F, Gerschlauer A, Madea B. Naphazoline intoxication in a child - a clinical and forensic toxicological case. Forensic Science International. 2003;134(2):234-7.

28. Nurmukhametov R.: Vasoconstrictors (decongestants). Consilium provisorum. 2001;1(1): 21-3.

29. Ogidigben MJ, Chu TC, Potter DE. Naphazoline-induced neuroendocrine changes: Increases in ANP and cGMP levels, but suppression of NE, $3 \mathrm{H}-\mathrm{NE}$, and cAMP levels in rabbit eyes. Pharmacology. 2002;65(3):155-61.

30. Ogidigben MJ, Chu TC, Potter DE. Naphazoline-induced suppression of aqueous humor pressure and flow: involvement of central and peripheral alpha(2)/I(1) receptors. Exp Eye Res. 2001;72(3):331-9.

31. Ono Y, Ono N, Shinohara K. Tissue hypoperfusion, hypercoagulopathy, and kidney and liver dysfunction after ingestion of a naphazoline-containing antiseptic. Case reports in emergency medicine 2017. 2017.

32. Ortego J, Coca-Prados M. Functional expression of components of the natriuretic peptide system in human ocular nonpigmented ciliary epithelial cells. Biochem Biophys Res Commun. 1999;258(1):21-8.

33. Pukhlik SM. Nasal Decongestants - Pros and Cons. Rhinology. 2004;4:36-51.

34. Putnam LE, Herwick RP. Privine dependence of two years' duration. JAMA. 1946; 130(11):702-3.

35. Radtsig EU, Ermilova NV, Sapaeva NV, Bogomil'sky MR. Alternative to topical decongestants for symptomatic treatment of children's acute rhinitis. Current pediatrics. 2007;6(5):92-5.

36. Ramey JT, Bailen E, Lockey RF. Rhinitis medicamentosa. J Investig Allergol Clin Immunol. 2006;16(3):148-55.

37. Rosati GF, Poletto MG. Pharmacological characteristics of alphamethyl-beta-[2-methylene-4,5-dihydroimidazoyl]. II Farmaco, Edizione Pratica. 1966;21(4):204-23.

38. Ruffolo RR. Distribution and function of peripheral $\alpha$-adrenoceptors in the cardiovascular system. Pharmacology Biochemistry and Behavior. 1985;22(5):827-33.

39. Sarchielli P, Alberti A, Codini M, Floridi A, Gallai V. Nitric oxide metabolites, prostaglandins and trigeminal vasoactive peptides in internal jugular vein blood during spontaneous migraine attacks. Cephalalgia. 2000;20(10):907-18.

40. Sortino S, Giuffrida S, Scaiano JC. Photogeneration of hydrated electrons, nitrogen-centered radicals and singlet oxygen from naphazoline: a laser flash photolysis study. Photochemistry and Photobiology. 1999;70(4):590-5.

41. Takeuchi K, Akatsuka K, Kasuya Y. Pharmacological studies of imidazoline derivatives. II. Actions on cardiovascular system and acute toxicity. J. Pharmacobiodyn. 1986;9(4):385-394.

42. Vitezic D, Rozmanic V, Franulovic J, Ahel V, Matesic D Naphazoline nasal drops intoxication in children. Arh Hig Rada Toksikol. 1994;45(1):25-9.

43. Warren MR, Werner HW. Acute toxicity of vasopressor amines II. Comparative data. J Pharmacol Exp Ther. 1946;86(3):280-3.

44. Watanabe Y, Hongo S, Matsumoto M. Evaluation of excised loach skin for studies on transdermal permeation of drugs in vitro. Yakugaku zasshi: Journal of the Pharmaceutical Society of Japan. 1989;109(9):656-61.

45. Wenzel S, Sagowski C, Laux G, Kehrl W, Metternich FU. Course and therapy of intoxication with imidazoline derivate naphazoline. Int J Pediatr Otorhinolaryngol. 2004;68(7):979-83.

46. Willems EW, Valdivia LF, Villalon CM, Saxena PR. Possible role of alpha-adrenoceptor subtypes in acute migraine therapy. Chephalalgia., 2003;23 (4):245-57.

47. Winston C. Hainsworth. Accidental poisoning with naphazoline («PRIVINE») hydrochlorid. Am J Dis Child. 1948;75(1):76-80. 
48. Yamadori Y, Oiso N, Hirao A, Kawara S, Kawada A. Allergic contact dermatitis from dibucaine hydrochloride, chlorpheniramine maleate, and naphazoline hydrochloride in an over-the-counter topical antiseptic. Contact Dermatitis. 2009;61(1):52-3.

49. Yonkman FF, Rennick B, Schwerma HL. Pharmacologic studies of a new vasoconstrictor: 2-naphthyl-(1')-methyl-imidazoline hydrochloride (Privine or Naphazoline): III. An attempt to localize the seat of action in terms of adrenergic and cholinergic foci. J Pharmacol Exp Ther. 1944;82(3):275-87.
50. Zarechnova N, Tursunov R. Study the impact of decongestants (naftizine) on the morphology of the mucosa of the nasal cavity of rats. Bulletin KRSU. 2012;12(2):163-6.

51. Zavala J A, Pereira ER, Zetola VH, Teive HA, Novak EM, Werneck LC. Hemorrhagic stroke after naphazoline exposition: case report. Arq Neuropsiquiatr. 2004;62(3B):889-91. 